\title{
Case Report on Secondary Peritonitis Caused by Jejunum Perforation
}

\author{
Pokhrel $A^{1 *}$, Neupane BR2 , Gupta $S^{3}$, Uprety $S^{4}$, Shrestha $A^{4}$ \\ ${ }^{1}$ Medical Officer, ${ }^{2}$ Professor \& HOD, ${ }^{4}$ Lecturer, Department of Surgery, ${ }^{3}$ Assistant Professor, Emergency Department, \\ Gandaki Medical College \& Teaching Hospital, Pokhara, Nepal
}

\author{
Keywords \\ Dudeno-jejunal flexure, Focus abdominal \\ sonography for trauma, Peritonitis.

\section{Corresponding author \\ *Dr. Amrit Prasad Pokhrel \\ Medical Officer, Department of Surgery \\ Gandaki Medical College \& Teaching \\ Hospital, Pokhara, Nepal \\ Email:pokhrel_amrit2011@gmail.com}

\begin{abstract}
The small intestine is third in frequency intraperitoneal organ injured after blunt trauma of abdomen. Peritonitis caused by isolated jejunum perforation is very rare. As most of these cases are accompanied with injuries with other structures in the abdomen, hence it is not suspected. Therefore failure in diagnosis and delay in treating these injuries significantly increase the morbidity and mortality of these patients. Here, we report a case of a 60 year old gentleman admitted in surgery department with severe abdominal pain, multiple episodes of vomiting followed to fast breathing and reduced consciousness. Our patient presented in septic shock, with toxic looks and clear cut rigid abdominal wall. To the best of our knowledge this is the first time we describe a case report on isolated jejunum perforation as a result of physical assault.
\end{abstract}

\section{INTRODUCTION}

Peritonitis is defined as the inflammation of peritoneum and peritoneal cavity, usually caused by a localized or generalized infection ${ }^{1}$. Secondary peritonitis is the inflammation of the peritoneum due to loss of integrity of gastro-intestinal tract i.e. GI perforation ${ }^{2}$. In blunt abdomen trauma, in majority of cases multiple abdominal organs are involved but isolated injury of jejunum perforation is extremely rare. As per the literature review on isolated jejunum perforation, it has been reported in only $<1 \%{ }^{3}$. The vast majority cases of intestinal perforation following blunt abdomen trauma is caused by motor vehicle accident, physical assault, fall injury, sport injury.

A sudden increase in intra-luminal pressure in a fluid or air filled bowel loop cause punctate or slit like perforation on the anti-mesenteric border. Most of the time these perforations are not surrounded by damage tissues because perforation occurs due to raised intraluminal pressure not due to crushing ${ }^{4}$. In unconscious patients with multiple injuries, the diagnosis of single isolated jejunum perforation is great dilemma. We can miss isolated jejunum perforation in blunt abdomen trauma cases because these days most of the solid organs injuries in hemodynamically stable patient managed conservatively 5 . Delay in diagnosis enhances significant morbidity and mortality. The clinical suspicion and early exploration in present case led to prompt surgical intervention and improve the prognosis of the patient.

\section{CASE PRESENTATION}

A 60 year old gentleman was referred to Emergency Department of Gankaki Medical College Teaching Hospital, Pokhara, Nepal, with history of abdominal pain and greenish vomiting for three days. He has been undergoing at the local hospital and managed under conservative treatment and as there was no improvement he was referred to our hospital. In emergency room, our patient was in septic shock with GCS of 10/15. Vitals: pulse: $108 / \mathrm{min}, \mathrm{B} / \mathrm{P}: 100 / 60 \mathrm{mmHg}$, temperature: $97.4^{\circ}$ f, respiratory rate: $26 / \mathrm{min}$, saturation of $84 \%$ on room air. Pain score of $8 / 10$. Per abdominal examinationinspection: absent abdominal movement, no external injury and bruises present, palpation: generalized tender all quadrant of abdomen, percussion: tympanic sound present, auscultation: absent bowel sound. Emergency resuscitation was started and routine investigations were performed. The chest $\mathrm{x}$-ray showed gas under diaphragm (Fig 1). Ultrasound sound scan of abdomen showed moderate ascites with dilated bowel loops present.

After thorough explaining of the problem and further management options with the relatives, we planned 
for emergency exploratory laparotomy and informed consent was taken from his son. Midline incision given above the umbilicus and abdomen was found to be filled of bilious fluid with feces and inflamed bowel. There was a perforation at $70 \mathrm{~cm}$ distal to dudeno-jejunal flexure at anti-mesenteric surface measuring about $1 \mathrm{X} 1 \mathrm{~cm}$. We had to extend the incision to infra-umbilical area. The perforation was repaired and peritoneal lavage was done. No further injury was present with normal abdominal viscera seen on operative findings. Abdominal drain tube was inserted. Post operatively patient developed symptoms of alcohol withdrawal.

On first post-operative day after patient consciousness was normal he explained the mechanism of his trauma was due to hit by elbow blow on his abdomen when there was dispute with a friend while he was drinking alcohol. He remembered the symptoms developed about an hour after the fight. On $18^{\text {th }}$ post operative day he was discharged and he followed up after two weeks with feeling almost back to normal.

Fig 1: Chest x-ray view shows crescent shape radiolucent shadow (Gas under diaphragm)

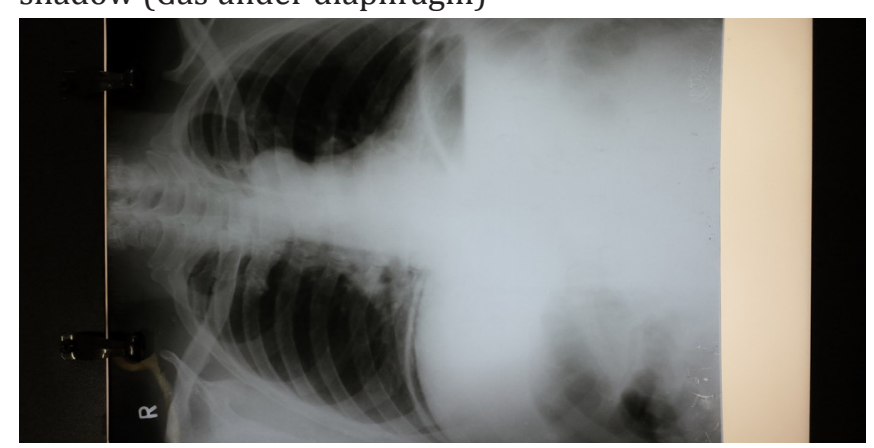

\section{DISCUSSION}

The abdomen is third most commonly injured part of body involved trauma. Early recognition of small bowel injury is important in the prevention of morbidity and mortality. Seventy five percent of blunt abdomen trauma is caused by motor vehicle accidents and rest by other mechanisms as explained ${ }^{5}$. Jejunum perforations occurs either due to physical assault by human being (in our case) or due to animal injury on abdomen, or due to bicycle handle bar injury are the most common etiology known in the literature. Single isolated jejunum perforation in blunt abdomen trauma is less than one percent ${ }^{6}$.

Mechanism of small bowel disruption with blunt trauma include shearing forces, compression forces between abdominal wall and vertebral column and blowout injury due to sudden increase in intra-luminal pressure of bowel loop ${ }^{4}$. The incidence of small bowel injury varies according to age group. For the early diagnosis of isolated jejunum perforation, detailed history and frequent clinical examination of abdomen are extremely useful, particularly in unconscious patients with other intra-abdominal solid organ injuries. Continuous abdominal pain, generalized abdominal tenderness and rigidity, repeated vomiting are the important signs of small bowel perforation.

Only physical examination is not sufficient for the diagnosis, as it is reliable in only $30 \%$ of blunt trauma injuries ${ }^{6}$. In early hours of injury, less than $50 \%$ of cases show free air, thus limiting the usefulness of erect x-ray chest or abdomen film. Apart from physical examination there are several methods for diagnosis of bowel perforation including Focused Abdominal Scan for Trauma (FAST). In our case we used it along with physical findings, computed tomography, diagnostic peritoneal lavage and diagnostic laparoscopy are other useful methods.

\section{CONCLUSIONS}

The present case report highlights the importance of detailed history and the specific mode of injury in the case of jejunum perforation. Immediate surgical exploration done by the Department of General Surgery in our hospital, although our patient presented after more than 72 hours of abdominal injury appropriately saved the life.

\section{REFERENCES}

1. D'Angelica M, Fong Y. The Liver. In: Townsend CM et al editors. Sabiston Textbook of Surgery. 18th ed. Philadelphia: Elsevier; 2008.p. 1489. Abdomen Chapter 45; page 1100.

2. Bailey and Love's Short Practice of Surgery. $26^{\text {th }}$ edition. Edited by Norman S. Williams, Christopher J. K. Bulstrode \& P. Ronan O' Connel. CRC Press.

3. Sunder Goyal, Snigdha Goyal, Garg MK. Single jejuna blowout perforation following blunt abdominal trauma: Diagnostic dilemma. Journal of Mahatma Gandhi Institute of Medical Sciences. Sep 2013; 18: 144-6.

4. Robbs JV, Moore SW, Pillay SP. Blunt abdominal trauma with jejunal injury: A review. J Trauma. 1980; 20: 308-11.

5. Fakhry SM, Brownstein M, Watts DD, Baker CC, Oller D. Relatively short diagnostic delays [8 hours] produce morbidity and mortality in blunt small bowel injury: An analysis of time to operative intervention in 198 patients from a multicenter experience. J Trauma. 2000; 48: 408-15.

6. Allen GS, Moore FA, Cox CS Jr, Wilson JT, Cohn JM, Duke JH. Hollow visceral injury and blunt trauma. J trauma. 1998; 45(1): 69-78. 